\title{
Hematopoietic stem cell transplantation completely reversed colitis but not arthritis in IL-10Ra deficiency
}

\author{
Vy H.D. Kim ${ }^{\mathrm{a}, \mathrm{b} *}$, Rae Brager ${ }^{\mathrm{a}}$, Julia Upton ${ }^{\mathrm{a}, \mathrm{b}}$, Bo Ngan ${ }^{\mathrm{c}}$, Andrea Newell ${ }^{\mathrm{b}, \mathrm{d}, \mathrm{e}}$, Maian Roifman ${ }^{\mathrm{f}}$, \\ Aleixo M. Muise ${ }^{\mathrm{g}, \mathrm{h}}$, Susanne M. Benseler', Eyal Grunebaum ${ }^{\mathrm{a}, \mathrm{b}, \mathrm{e}}$, and Chaim M. \\ Roifman ${ }^{\mathrm{a}, \mathrm{b}, \mathrm{d}, \mathrm{e}}$
}

\begin{abstract}
Mutations in IL-10R1, IL-10R2, and IL-10 have been identified in infants with severe colitis. The only possible hope for cure in these conditions is a hematopoietic stem cell transplantation (HSCT). We report here on a patient with IL-10R1 deficiency who suffered severe colitis and arthritis. She received a HSCT from a matched unrelated donor and her post-transplant course was uneventful. She has fully engrafted and her immune reconstitution was complete and robust. Although signs of colitis were completely resolved, arthritis was not reversed by HSCT. She continues to have joint swelling in the knees and inflammatory changes in the wrists. In conclusion, HSCT seems to have reversed colitis, but was insufficient to improve arthritis and possibly other autoimmune manifestations.

Statement of novelty: This report describes a successful HSCT in severe infantile colitis caused by mutations in IL-10R1. Yet, the arthritis remains active, suggesting that conditions such as severe rheumatic disorders in childhood may not be reversed by replacement of the hematopoietic system.
\end{abstract}

\section{Introduction}

Inflammatory bowel disease can be defined in phenotypical subgroups including ulcerative colitis, Crohn's disease, and indeterminate or nonspecific colitis (Podolsky 2007; Xavier and Podolsky 2007). Recent genome-wide genetic linkage and association studies revealed aberrations in a host of functionally diverse genes that likely render individuals susceptible to these disorders (Hugot et al. 2001; Stoll et al. 2004; Duerr et al. 2006; Hampe et al. 2007; Parkes et al. 2007; Cho 2008; Franke et al. 2008; Kaser et al. 2008; Moran et al. 2013). a Division of Immunology and Allergy, Department of Paediatrics, The Hospital for Sick Children, The University of Toronto, Toronto, ON, Canada; ${ }^{\mathrm{b}}$ The Canadian Centre for Primary Immunodeficiency, The Hospital for Sick Children, The University of Toronto, Toronto, ON, Canada; ${ }^{\mathrm{C}}$ Department of Paediatric Laboratory Medicine, The Hospital for Sick Children, The University of Toronto Toronto, ON, Canada; ${ }^{\mathrm{d}}$ The Jeffrey Modell Research Laboratory for the Diagnosis of Primary Immunodeficiency, The Hospital for Sick Children, The University of Toronto, Toronto, ON, Canada; ${ }^{~}$ Department of Immunology The Hospital for Sick Children, The University of Toronto, Toronto, ON Canada; ${ }^{f}$ Division of Clinical and Metabolic Genetics, Department of Paediatrics, The Hospital for Sick Children, The University of Toronto, Toronto, ON, Canada; ${ }^{9}$ Division of Gastroenterology, Hepatology, and Nutrition, Department of Paediatrics, The Hospital for Sick Children, The University of Toronto, Toronto, ON, Canada; ${ }^{\mathrm{h}}$ SickKids Inflammatory Bowel Disease Center and Cell Biology Program, Research Institute, The Hospital for Sick Children, The University of Toronto, Toronto, ON, Canada; 'Division of Rheumatology, Department of Paediatrics, The Hospital for Sick Children, The University of Toronto, Toronto, ON, Canada
Submitted 23 September 2014

Accepted 23 September 2014

Available online 2 October 2014 
The relative contribution of each of these genetic abnormalities to the clinical phenotype is currently unknown.

Severe inflammatory colitis can also be associated with so-called monogenic disorders in humans and mice (Kuhn et al. 1993; Hugot et al. 2001; Stoll et al. 2004; Duerr et al. 2006; Hampe et al. 2007; Parkes et al. 2007; Cho 2008; Franke et al. 2008; Kaser et al. 2008; Moran et al. 2013). Loss of function mutations in interleukin (IL) -2R $\alpha$ (Roifman 2000) and FOXP3 (Bennett et al. 2001) lead to uncontrolled inflammation such as severe enteritis, nephritis, endocrinopathy, or other autoimmune manifestations. A major underlying mechanism in these diseases is the paucity or dysfunction of T-regulatory cells (T-regs). T-regs suppress excess inflammatory responses after antigen-mediated activation of effector CD4+ T cells, including Th17 cells. In T-regs, activated STAT3 and FOXP3 co-operatively regulate a subset of genes that empower these cells with the ability to suppress Th17-cell-mediated inflammation (Chaudhry et al. 2009). Critical for the induction of Th17 cell responses is the activation of STAT3 transcription factor downstream of pro-inflammatory cytokines such as IL-6, IL-21, and IL-23. Indeed, T-reg specific deletion of STAT3 results in a fatal Th17-celldriven colitis in mice (Chaudhry et al. 2011). Th17cell-mediated inflammation is also controlled by IL- 10 . It has been demonstrated that the IL-10 receptor was required for T-reg mediated suppression of Th17-celldriven colitis (Huber et al. 2011). IL-10 is secreted by a variety of cell types, and it has been shown to limit the secretion of the pro-inflammatory cytokines such as tumor necrosis factor $\alpha(\mathrm{TNF} \alpha)$ and IL-12.

The receptor for IL-10 consists of 2 alpha chains (IL10R1) and 2 beta molecules (IL-10R2) (Moore et al. 2001). Although IL-10R1 is specific to the IL-10 receptor, IL10-R2 is shared by other receptors such as IL-22 and IL-26. Mice deficient in either IL-10 or IL-10R2 suffer severe enterocolitis (Kuhn et al. 1993). Similarly, mutations in $I L-10 R 1, I L-10 R 2$, and $I L-10$ have been identified in infants with severe colitis (Fiorentino et al. 1989; Murai et al. 2009; Glocker et al. 2009; Begue et al. 2011; Moran et al. 2012; Kotlarz et al. 2012).

Patients with exaggerated inflammation may benefit from hematopoietic stem cell transplantation (HSCT). It was first demonstrated in IL-2R $\alpha$ deficiency (Roifman 2000) and thereafter in patients with mutations in FOXP3. Recently, early experience with HSCT using modified conditioning in IL-10 pathway defects has been reported (Kotlarz et al. 2012). However, the cohorts are very small, and long-term outcomes are yet to be established.

We report here our experience with full myeloablative conditioning followed by matched unrelated HSCT in a patient with IL-10R1 deficiency.

\section{Methods}

\section{Data retrieval}

The patient was treated primarily at the Hospital for Sick Children, Toronto, Ontario. Consent was obtained from the patient and her parents for inclusion in the Canadian Centre for Primary Immunodeficiency (CCPID) Registry and tissue bank, which has been approved by the SickKids Research Ethics Board (protocol No. 1000005598). Data from medical records were compiled prospectively and retrospectively, and entered into the CCPID Registry.

\section{Lymphocyte markers and T-cell proliferative responses}

Blood mononuclear cells were obtained using FicollHypaque density gradient centrifugation and the surface phenotypes were determined using direct immunofluorescence with fluorescein isothiocyanate conjugated MoAbs anti-CD3, CD4, CD8, CD20, and CD56 (Coulter Instruments, Mississauga, Ontario). Analysis was performed on a Coulter EPICS V flow cytometer. Lymphocyte proliferation response to phytohaemagglutinin (PHA) was assessed by tritiated thymidine incorporation using the microtitre plate technique. All assays were performed in triplicate and compared with normal controls that were performed at the same time.

\section{Analysis of T-cell receptor (TCR) repertoire}

TCR V $\beta$ families within CD4+ and CD8+ subpopulations were investigated using flow cytometry as previously described in Roifman et al. (2006)

\section{Sequence analysis}

The patient's genomic DNA was analyzed by polymerase chain reaction (PCR) amplification and direct sequencing of the $I L-10 R 1$ gene. PCR primers were designed to amplify a genomic DNA fragment between 30 and 60 bp upstream and downstream of each transcript exon of the IL-10R1 gene. The PCR conditioning 
consisted of $94{ }^{\circ} \mathrm{C}$ for $30 \mathrm{~s}, 55^{\circ} \mathrm{C}$ for $30 \mathrm{~s}$, and $68^{\circ} \mathrm{C}$ for $2 \mathrm{~min}$, for a total of 35 cycles using Elongase (Invitrogen).

PCR products were electrophoresed on $0.8 \%$ agarose gels. Each PCR fragment was then cut and purified using QIAquick Gel Extraction Kit (QIAGEN). For mutation detection, each purified PCR fragment was autosequenced with a DTCS Quick Kit using the same PCR primers (Beckman-Coulter CEQ8000).

\section{Results}

\section{Case}

The patient was born after a spontaneous vaginal delivery at 30 weeks gestation to nonconsanguineous parents of English descent. Family history was significant for thyroid disease in a maternal aunt and gestational diabetes in the mother. At the age of 3 weeks the patient was admitted to the hospital for periorbital cellulitis. It was noted she had a presumed candida infection of her skin on the back of her neck, both axillae, and groin areas with satellite lesions that responded to treatment with nystatin. At 4 weeks of age she suffered an exacerbation of cellulitis complicated by meningitis. She fully recovered after antibiotic therapy.

At 3 months of age she was readmitted for purulent left ear discharge. Cultures of the discharge grew Staphylococcus aureus. At 4 months of age, she was admitted for extensive erythroderma that was most prominent on the head, neck, torso, and extremities (Figure 1). Swabs of the skin lesion grew Klebsiella pneumonia and Enterococcus. It was noted she had enlarged lymph nodes in the axillae and groin. She responded partially to steroids in combination with topical antifungal treatment.

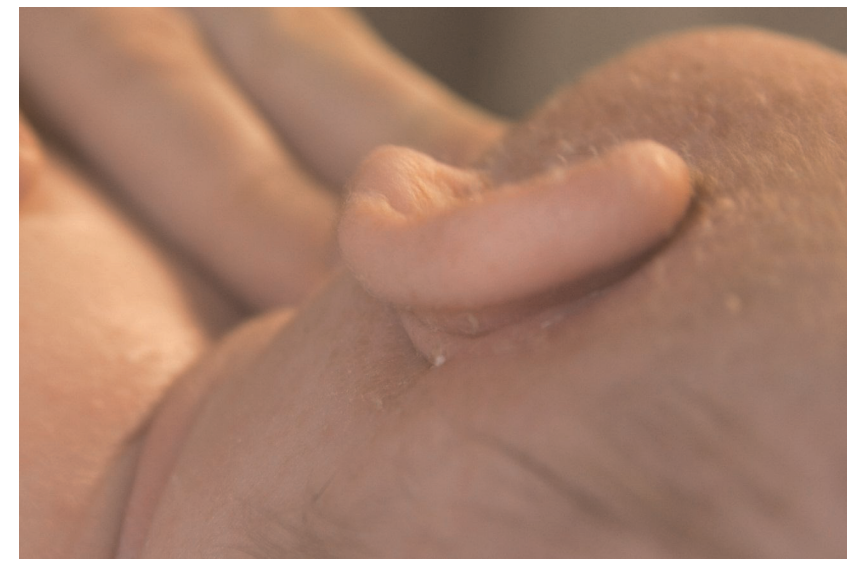

Figure 1: Erythroderma as manifested by extensive scaling and erythema of the skin.
At 7 months of age she was admitted with a history of diarrhea and rectal bleeding that worsened over a period of 6 weeks. She was found to have perianal skin tags and fissures, leading to significant discomfort with stooling (Figure 2). The diarrhea until this stage was intermittent.

From 8 to 12 months of age, she continued to have repeated episodes of fever and diarrhea that seemed to have responded initially to treatment with antibiotics. When symptoms became refractory to antibiotics she received sulfasalazine with apparent worsening of symptoms.

She was then placed on systemic steroids (1 mg. $\mathrm{kg}^{-1} \cdot \mathrm{day}^{-1}$ ) with good response, but repeated attempts to wean her off steroids resulted in exacerbation of her symptoms.

At 15 months of age she developed arthritis with significant effusions in her knees and involvement of her elbows (Figure 3). Steroid joint injections controlled symptoms transiently and treatment with anakinra failed to control the arthritis.



Figure 2: Peri-anal examination pretransplant revealed an anal fissure and 2 pedunculated skin tags.



Figure 3: Bilateral knee effusions, pretransplant. 
Over the ensuing 6 months she developed 4 perianal fistulae (Figure 4). To allow for healing of the perianal area, a diverting ileostomy was performed. Unfortunately, in spite of this procedure, bloody diarrhea continued and the perianal area did not heal. Moreover, the surrounding area of the ileostomy became aggressively inflamed. Her deterioration and lack of adequate response to conservative treatment prompted consideration of HSCT.

\section{Evaluation of immunity}

The presentation with severe infections so early in life triggered a rigorous evaluation of the patient's immune system, with suspicion of a primary immunodeficiency. Her lymphocyte count was consistently high, ranging from 5 to $7 \times 10^{3}$ cells. $\mu \mathrm{L}^{-1}$. Numbers of $\mathrm{CD} 4^{+}$cells were consistently elevated between 4490 and 5106 cells $\mu \mathrm{L}^{-1}$, with a relative paucity of $\mathrm{CD} 8^{+}$cells $(7.5 \%$ of $\mathrm{CD}^{+}$cells). B-cell numbers were also elevated.

T-cell receptor excision circle levels were normal, suggesting adequate thymopoiesis. Evaluation of the TCR repertoire revealed clonal expansion of several $\mathrm{V} \beta$ families, reminiscent of autoimmune disorders (Figure 5). Stimulation index of in-vitro responses to PHA were reduced compared with control samples, but this was mainly attributed to a high background, likely related to activated $\mathrm{T}$ cells.

Upon exposure to egg, the patient had an episode of cyanosis and breathing difficulties consistent with type 1 hypersensitivity reaction. A whole egg extract skin-

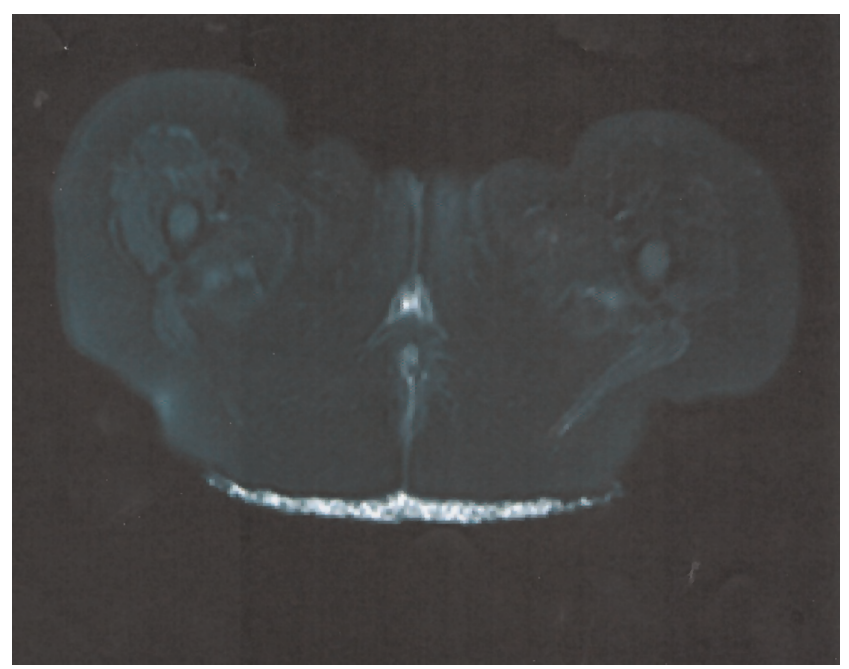

Figure 4: T2 STIR MRI demonstrating a posterior perianal fistula pretransplant. prick test was strongly $(+3)$ positive. ImmunoCAPradioallergosorbent test (CAP-RAST) test to egg white and egg yolk were positive.

Accidental exposure to cow's milk triggered a severe episode of diarrhea and vomiting. Skin-prick testing performed at 13 months of age was strongly positive to fresh cow's milk $(+4)$ and cow's milk extract $(+3)$.

\section{Genetic analysis}

Sanger sequencing of $I L-10 R 1$ revealed a homozygous mutation in intron 5 at the conserved GT splice donor site c. $(688+2 \mathrm{~T}>\mathrm{C})$ (Figure 6). This mutation of the invariant dinucleotide GT at the $5^{\prime}$-splice donor site alters normal splicing and creates a cryptic splice site as previously described in Moran et al. (2012).

The predicted aberrant protein contains only the extracellular domain of IL-10R1.

\section{Description of colitis}

Biopsies performed through colonoscopy at 8 months of age showed colonic mucosa that had mild
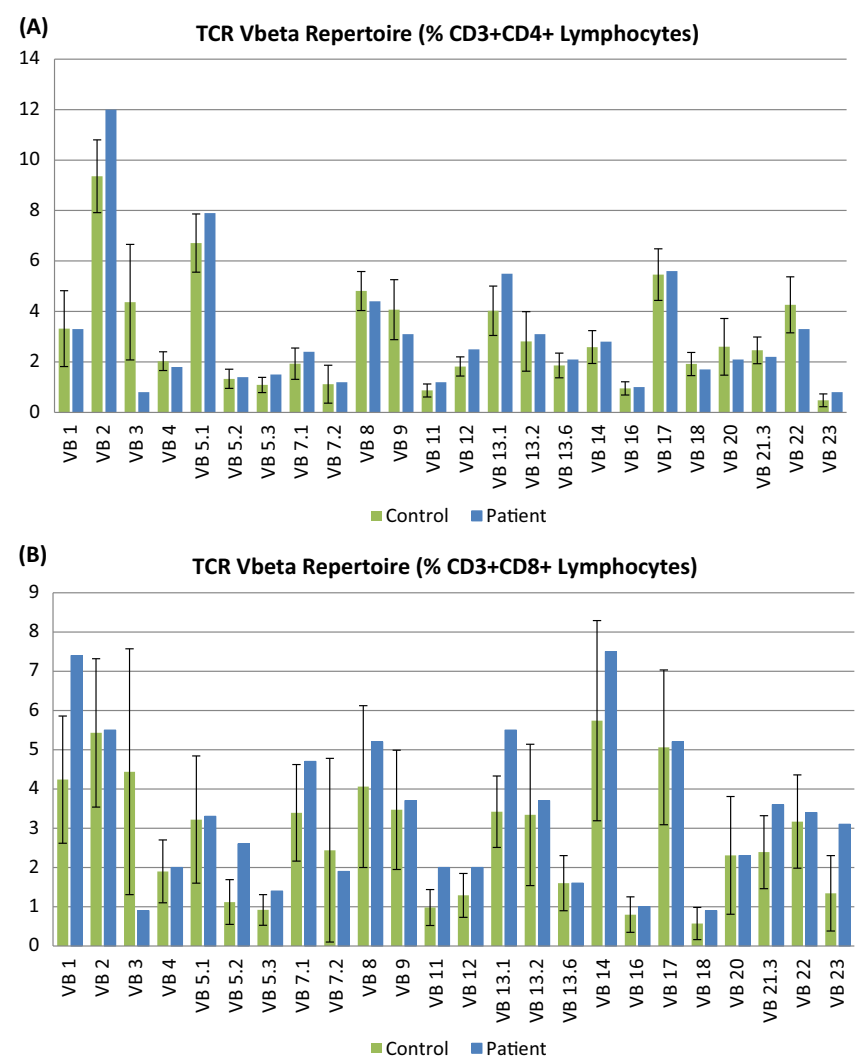

Figure 5: T-cell receptor repertoire revealed clonal expansion of several $\mathrm{V} \beta$ families in CD3 + CD4+ T cells (A) and CD3 + CD4+ T cells (B). 




Figure 6: Electropherogram of wild type vs. patient sequence showing the homozygous mutation c. $[688+2 \mathrm{~T}>\mathrm{C}] ;[688+2 \mathrm{~T}>$ C] in IL-10RA (NM_001558.3) (A). Human IL-10RA showing the Tissue factor; pfam01108 Domain, interferon-alpha/beta receptor fibronectin-type III; pfam09294 Domain and the Transmembrane Domain (TM), their boundaries and the location of the c. $[688+2 \mathrm{~T}>\mathrm{C}] ;[688+2 \mathrm{~T}>\mathrm{C}]$ mutation $(\mathrm{B})$.

architectural disarray of glands with focal branching but a well-preserved goblet cell population. The lamina propria showed a mild increase of mixed infiltration of inflammatory cells with focal aggregates of eosinophils. The surface epithelium showed mild exudates of neutrophils and fibrin, suggesting exudation into the lumen. There was no evidence of ulceration. The features suggested mild, acute nonspecific colitis.

Biopsies obtained at 17 months of age showed that the glands throughout were generally elongated and showed reduction of goblet cell population. The most inflamed portion of the gut identified was in the cecum, where there were heavy aggregates of neutrophils in the lamina propria and crypt abscesses (Figures 7 and 8). Focal and sporadic crypt abscesses were also noted in the descending and ascending colon, sigmoid, and rectum. There was continuous severe grade 3 colitis with multiple large serpiginous ulcers in the rectum and sigmoid colon.

Perianal examination revealed a long pedunculated skin tag and chronic fissures at multiple sites (Figure 2).

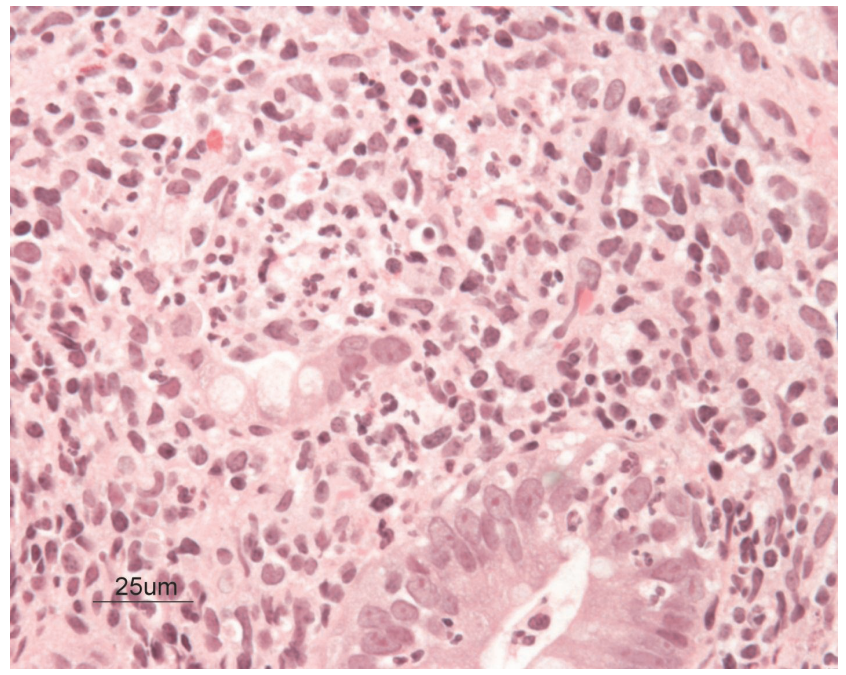

Figure 7: Colonic mucosa shows acute cryptitis (right side of field) where neutrophils infiltrate the crypt epithelium. To its left side, severe acute inflammation is present where neutrophils infiltrate, expand, and partially destroy another colonic glandular crypt. Only part of the crypt epithelium remains

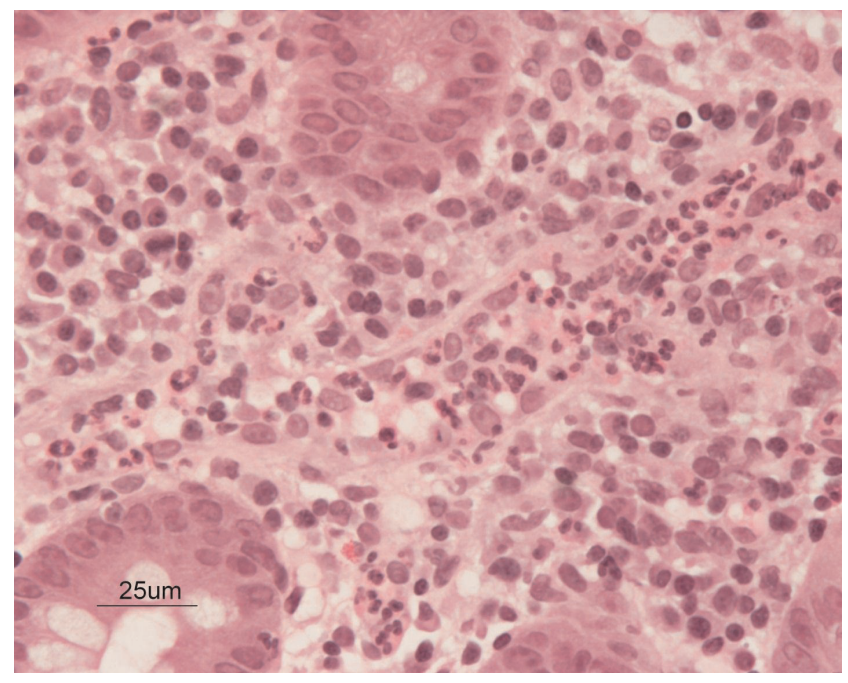

Figure 8: The lamina propria of the colon is heavily infiltrated by acute and chronic inflammatory cells. In particular in focal capillary beds (as shown here), active capillariitis with marked increased in neutrophils that exhibits margination and emigration from a capillary with reactive endothelial cell changes is seen. The integrity of this capillary is maintained as there is no extravasation of red blood cells. No fibroid necrosis is evident. This feature is a frequent feature of inflammatory bowel disease.

\section{Skin manifestations}

A skin biopsy was performed in which the epidermis showed psoriasiform acanthosis, patchy parakeratosis associated with collection of neutrophils in the 
parakeratotic layer, and minimal exocytosis of lymphocytes and eosinophils. There were patchy foci of spongiosis associated with lymphocytes. An occasional necrotic keratinocyte was seen. The papillary dermis was edematous and had a mild-to-moderate perivascular and interstitial infiltrate of lymphocytes with fewer eosinophils and neutrophils. Special stains for bacterial and fungal organisms were negative. Immunohistochemical stains revealed loss of $\mathrm{CD} 7$ and paucity of CD8+ cells. The majority of the cells in the dermal infiltrate were positive for CD2, CD3, CD4, and CD5. Molecular immunoglobulin and T-cell receptor rearrangement studies revealed monoclonality in both cell types suggesting aberrant lymphocyte expansion or malignancy.

\section{Hematopoeitic stem cell transplantation}

With no human leukocyte antigen (HLA)-matched donor in the immediate family, we elected to use a 10/ 10 antigen matched unrelated donor (MUD). The patient received myeloablative conditioning with busulfan and cyclophosphomide as well as graft-versus-host disease (GvHD) prophylaxis with cyclosporine and prednisone. Engraftment was rapid, starting with neutrophils on day +9 . Her last transfusion of red cells and platelets was on day +10 and day +16 posttransplantation, respectively.

The transplant course was uneventful with the exception of one major episode of gastrointestinal bleeding. Although GvHD was considered in the differential diagnosis, we elected not to add immunosuppressive agents and she subsequently recovered spontaneously. Abdominal pain, frequent stooling, and bloody diarrhea completely resolved within less than 1 month following transplantation. The perianal inflammation and fistulas also resolved. Doses of cyclosporine and steroids were gradually reduced and the severe cushingnoid features disappeared. At 5 months post-transplant her small bowel was surgically re-anastomosed and all incisions healed quickly.

Two years post-transplant, she maintained a robust engraftment with $100 \%$ donor cells in the circulation. Evaluation of the immune system revealed normal numbers of circulating $\mathrm{CD}^{+} \mathrm{T}$ cells as well as normal in-vitro responses to mitogens.

An attempt to discontinue steroid treatment resulted in a breakthrough of her joint inflammation. She complained again of morning stiffness, and on examination moderate effusions in the knees and wrists were noted. In addition, a large patch of skin hypopigmentation (vitiligo) was identified on her left elbow (Figure 9).

\section{Discussion}

IL-10, initially recognized for its inhibitory activity on effector function of $\mathrm{T}$ cells (Murai et al. 2009) and macrophages, was later found to have diverse effects on most hematopoietic cell types (Fiorentino et al. 1989; Asseman et al. 1999; Annacker et al. 2001; De Winter et al. 2002; Grimbaldeston et al. 2007; Rubtsov et al. 2008). IL-10 also plays a major role in differentiation and function of T-regs. Inflammatory bowel diseases as well as other exaggerated inflammatory processes were demonstrated in IL-10-deficient mice, which confirmed that the major role of IL-10 is to limit inflammatory responses (Kuhn et al. 1993). Indeed, mutations in IL-10 or its receptors, IL-10R1 or IL$10 \mathrm{R} 2$, were found in infants with severe inflammatory bowel disease (Glocker et al. 2009, Moran et al. 2012; Kotlarz et al. 2012).

We reported here in detail the clinical course including HSCT of a patient with IL-10R1 deficiency. Because infantile colitis is frequently fatal in spite of medical treatments, attempts have been made to cure the condition with HSCT. Early studies in mice suggested that this might be a plausible approach (Mottet et al. 2003). Indeed, 7 patients with IL-10R1 or IL-10R2 deficiency who received transplants from matched related or matched unrelated donors have been recently reported (Kotlarz et al. 2012). Patients received nonmyeloablative conditioning and reported follow-up time is too short to



Figure 9: A hypopigmented patch of skin appears posttransplant over the left elbow. 
draw any conclusions. However, 3 of 4 patients who received MUD had graft failure and needed a second infusion of stem cells. Nevertheless, improvement of gut symptoms appeared universal.

Because of the high frequency of acute GvHD in MUD transplants, we anticipated major complications in this patient, particularly because of the pre-existing severe enterocolitis. To ascertain sustained engraftment, our protocol included myeloablative conditioning with cyclophosphomide and busulfan. The combination of cyclosporine and prednisone was used for GvHD prophylaxis. Surprisingly, the post-transplantation course was uneventful with no GvHD. Severe colitis resolved completely within 4 weeks of transplantation. In contrast, weaning of steroids down to $10 \mathrm{mg}$ every other day resulted, unexpectedly, in a breakthrough of symptoms such as morning stiffness and gradual increased swelling of knees and wrists. Intra-articular injections of steroids controlled symptoms transiently but the patient required systemic steroids to suppress joint inflammation.

It is not immediately clear why inflammation in the gut completely reversed after HSCT but arthritis did not. The resistance of arthritis to treatment with HSCT is intriguing. Based on the $\mathrm{TH}_{1} \mathrm{~T}$-cell abundance in the synovium, replenishing IL-10, which is a prototypic $\mathrm{TH}_{2}$ cytokine, we would have predicted improvement of arthritis but this did not occur in our patient. This may suggest that this failure may not be related solely to availability of IL-10 in the joints as previously speculated in IL-10 treatment models for rheumatoid arthritis (Smeets et al. 1999).

Moreover, in theory, all recipient $\mathrm{T}$ cells as well as macrophages should be substituted with donor cells after myeloablative conditioning followed by a HSCT. If this was achieved in our patient, as evidenced by the robust engraftment, then it would suggest that replacing $\mathrm{T}$ cells and macrophages may not be sufficient to arrest pre-existent inflammation in the joints. Although there is ample evidence for involvement of T cells in the process of the development of arthritis (Stastny 1976; Nepom et al. 1989; Weyand et al. 1992), their role in propagation of the disease remains unclear. Indeed, one hypothesis for long standing disease that leads to a destructive phase is that this process may become independent of antigen stimulation and canonical immune responses (Firestein and Zvaifler 1990). This process may be locally controlled by synoviocytes and osteoclasts, and it may be propagated by autocrine and paracrine systems involving IL-1, TNF $\alpha$, GM-CSF, various chemokines, and other factors (Firestein 2003). The fibroblast-like synoviocytes in the intimal lining produce factors that can maintain inflammation by activating cells in their environment. Neighbouring cells are induced to express and secret other cytokines, metalloproteinases, prostaglandins, and nitric oxide contributing to the process (Firestein and Zvaifler 1990; Firestein 2003).

An alternative possibility is that recipient local intra-articular macrophages that play a major role in inflammation may have survived the myeloablative conditioning. More speculative is the remote event that donor cells contained genetic aberrations known to render individuals more susceptible to arthritis.

Regardless of the reason, it is important to educate physicians as well as patients about the possibility of a failure to reverse some autoimmune manifestations in these disorders.

In summary we demonstrated here that: (i) HSCT with a MUD can be safely and successfully used to replace the immune system in IL10R1 deficiency, (ii) the potentially fatal colitis resolved completely within weeks of transplantation, (iii) myeloablative conditioning enabled a robust engraftment and immune reconstitution without toxicity, and (iv) pre-existing arthritis was not reversed.

\section{REFERENCES}

Annacker, O., Pimenta-Araujo, R., Burlen-Defranoux, O., Barbosa, T.C., Cumano, A., and Bandeira, A. 2001. CD25+CD4+ T cells regulate the expansion of peripheral CD4 $\mathrm{T}$ cells through the production of IL-10. J. Immunol. 166(5):3008-3018. PMID: 11207250. doi: 10.4049/jimmunol.166.5.3008.

Asseman, C., Mauze, S., Leach, M.W., Coffman, R.L., and Powrie, F. 1999. An essential role for interleukin 10 in the function of regulatory $\mathrm{T}$ cells that inhibit intestinal inflammation. J. Exp. Med. 190:995-1004. PMID: 10510089. doi: 10.1084/jem.187.7.1047.

Begue, B., Verdier, J., Rieux-Laucat, F., Goulet, O., Morali, A., Canioni, D., Hugot, J.P., Daussy, C., Verkarre, V., Pigneur, B., Fischer, A., Klein, C., CerfBensussan, N., and Ruemmele, F.M. Defective IL10 signaling defining a subgroup of patients with inflammatory bowel disease. Am. J. Gastroenterol. 106: 1544-1555. 
Bennett, C.L., Christie, J., Ramsdell, F., Brunkow, M.E., Ferguson, P.H., Whitesell, L., Kelly, T.E., Saulsbury, F.T., Chance, P.F., and Ochs, H.D. 2001. The immune dyregulation, polyendocrineopathy, enteropathy, Clinked syndrome (IPEX) is caused by mutations of FOXP3. Nat. Genet. 27(1):20-21. PMID: 11137993. doi: $10.1038 / 83713$.

Chaudhry, A., Rudra, D., Treuting, P., Samstein, R.M., Liang, Y., Kas, A., and Rudensky, A.Y. 2009. CD4+ regulatory T cells control TH17 responses in a Stat3dependent manner. Science. 326(5955):986-991. PMID: 19797626. doi: 10.1126/science.1172702.

Chaudhry, A., Samstein, R.M., Treuting, P., Liang, Y., Pils, M.C., Heinrich, J.M., Jack, R.S., Wunderlich, F. T., Brüning, J.C., Müller, W., and Rudensky, A. Y. 2011. Interleukin-10 signalling in regulatory $\mathrm{T}$ cells is required for suppression of Th17 cell -mediated inflammation. Immunity. 34(4):566-578. PMID: 21511185. doi: 10.1016/j.immuni.2011.03.018.

Cho, J.H. 2008. The genetics and immunopathogenesis of inflammatory bowel disease. Nat. Rev. Immunol. 8(6):458-466. PMID: 18500230. doi: 10.1038/nri2340. De Winter, H., Elewaut, D., Turovskaya, O., Huflejt, M., Shimeld, C., Hagenbaugh, A., Binder, S., Takahashi, I., Kronenberg, M., and Cheroutre, H. 2002. Regulation of mucosal immune responses by recombinant interleukin 10 produced by intestinal epithelial cells in mice. Gastroenterology. 122(7):1829-1841. PMID: 12055591. doi: 10.1053/gast.2002.33655.

Duerr, R.H., Taylor, K.D., Brant, S.R., Rioux, J.D., Silverberg, M.S., Daly, M.J., Steinhart, A.H., Abraham, C., Regueiro, M., Griffiths, A., Dassopoulos, T., Bitton, A., Yang, H., Targan, S., Datta, L.W., Kistner, E.O., Schumm, L.P., Lee, A.T., Gregersen, P.K., Barmada, M.M., Rotter, J.I., Nicolae, D.L., and Cho, J.H. 2006. A genome-wide association study identifies IL23R as an inflammatory bowel disease gene. Science. 314(5804):1461-1463. PMID: 17068223. doi: $10.1126 /$ science. 1135245 .

Fiorentino, D.F., Bond, M.W., and Mosmann, T.R. 1989. Two types of mouse T helper cell. IV. Th2 clones secrete a factor that inhibits cytokine production by Th1 clones. J. Exp. Med. 170(6): 2081. doi: 10.1084/jem.170.6.2081.

Firestein, G.S. 2003. Evolving concepts of rheumatoid arthritis. Nature. 423(6937):356-361. PMID: 127 48655. doi: $10.1038 /$ nature 01661 .

Firestein, G.S., and Zvaifler, N.J. 1990. How important are $\mathrm{T}$ cells in chronic rheumatoid synovitis? Arthritis Rheum. 33(6):768-773. PMID: 2194461. doi: 10.1002/ art.1780330602.
Franke, A., Balshun, T., Karlsen, Sventoraityte, J., Nikolaus, S., Mayr, G., Domingues, F.S., Albrecht, M., Nothnagel, M., Ellinghaus, D., Sina, C., Onnie, C.M., Weersma, R.K., Stokkers, P.C., Wijmenga, C., Gazouli, M., Strachan, D., McArdle, W.L., Vermeire, S., Rutgeerts, P., Rosenstiel, P., Krawczak, M., and Vatn, M.H. 2008. Sequence variants in IL10, ARPC2 and multiple other loci contribute to ulcerative colitis susceptibility. Nat Genet. 40:1319-1323.

Glocker, E.O., Kotlarz, D., Boztug, K., Gertz, E.M., Schäffer, A.A., Noyan, F., Perro, M., Diestelhorst, J., Allroth, A., Murugan, D., Hätscher, N., Pfeifer, D., Sykora, K.W., Sauer, M., Kreipe, H., Lacher, M., Nustede, R., Woellner, C., Baumann, U., Salzer, U., Koletzko, S., Shah, N., Segal, A.W., Sauerbrey, A., Buderus, S., Snapper, S.B., Grimbacher, B., and Klein, C. 2009. Inflammatory bowel disease and mutations affecting the interleukin-10 receptor. N. Engl. J. Med. 361(21):2033-2045. doi: 10.1056/NEJMoa090 7206.

Grimbaldeston, M.A., Nakae, S., Kalesnikoff, J., Tsai, M., and Galli, S.J. 2007. Mast cell-derived interleukin 10 limits skin pathology in contact dermatitis and chronic irradiation with ultraviolet. B Nat. Immunol. 8(10):1095-1104. doi: 10.1038/ni1503.

Hampe, J., Franke, A., Rosenstiel, P., Till, A., Teuber, M., Huse, K., Albrecht, M., Mayr, G., De La Vega, F. M., Briggs, J., Günther, S., Prescott, N.J., Onnie, C.M., Häsler, R., Sipos, B., Fölsch, U.R., Lengauer, T., Platzer, M., Mathew, C.G., Krawczak, M., and Schreiber, S. 2007. A genome-wide association scan of nonsynonymous SNPs identifies a susceptibility variant for Crohn disease in ATG16L11. Nat. Genet. 39(2):207-211. PMID: 17200669. doi: 10.1038/ng 1954.

Huber, S., Gagliani, N., Esplugues, E., O'Connor, W. Jr., Huber, F.J., Chaudhry, A., Kamanaka, M., Kobayashi, Y., Booth, C.J., Rudensky, A.Y., Roncarolo, M.G., Battaglia, M., and Flavell, R.A. 2011. Th17 cells express interleukin-10 receptor and are controlled by Foxp $3^{-}$and Foxp $3^{+}$regulatory $\mathrm{CD} 4+\mathrm{T}$ cells in an interleukin-10 dependent manner. Immunity. 34 (4):554-565. PMID: 21511184. doi: 10.1016/j.immuni. 2011.01.020.

Hugot, J.-P., Chamaillard, M., and Zouali, H. 2001. Association of NOD2 leucine-rich repeat variants with susceptibility to Crohn's disease. Nature. 411:599-603. PMID: 11385576 . doi: 10.1038/35079107.

Kaser, A., Lee, A.-H., Franke, A., Glickman, J.N., Zeissig, S., Tilg, H., Nieuwenhuis, E.E., Higgins, D.E., Schreiber, S., Glimcher, L.H., and Blumberg, 
R.S. 2008. XBP1 links ER stress to intestinal inflammation and confers genetic risk for human inflammatory bowel disease. Cell. 134(5):743-756. PMID: 18775308. doi: 10.1016/j.cell.2008.07.021.

Kotlarz, D., Beier, R., Murugan, D., Diestelhorst, J., Jensen, O., Boztug, K., Pfeifer, D., Kreipe, H., Pfister, E.D., Baumann, U., Puchalka, J., Bohne, J., Egritas, O., Dalgic, B., Kolho, K.L., Sauerbrey, A., Buderus, S., Güngör, T., Enninger, A., Koda, Y.K., Guariso, G., Weiss, B., Corbacioglu, S., Socha, P., Uslu, N., Metin, A., Wahbeh, G.T., Husain, K., Ramadan, D., AlHerz, W., Grimbacher, B., Sauer, M., Sykora, K.W., Koletzko, S., and Klein, C. 2012. Loss of Interleukin10 signaling and infantile inflammatory bowel disease: implications for diagnosis and therapy. Gastroenterology. 143(2):347-355. PMID: 22549091. doi: 10.1053/j. gastro.2012.04.045.

Kuhn, R., Lohler, J., Rennick, D., Rajewsky, K., and Müller, W. 1993. Interleukin-10-deficient mice develop chronic enterocolitis. Cell. 75(2):263-274. PMID: 8402911. doi: 10.1016/0092-8674(93)80068-P.

Moore, K.W., deWaal Malefyt, R., Coffman, R.L., and O'Garra, A. 2001. Interleukin-10 and the Interleukin-10 receptor. Annu. Rev. Immuno. 19:683-765. doi: 10.1146/annurev.immunol.19.1.683.

Moran, C.J., Walters, T.D., Guo, C.H., Kugathasan, S., Klein, C., Turner, D., Wolters, V.M., Bandsma, R.H., Mouzaki, M., Zachos, M., Langer, J.C., Cutz, E., Benseler, S.M., Roifman, C.M., Silverberg, M.S., Griffiths, A.M., Snapper, S.B., and Muise, A.M. 2013. IL-10R polymorphisms are associated with very-early-onset ulcerative colitis. Inflamm. Bowel. Dis. 19(1):115123. PMID: 22550014. doi: 10.1002/ibd.22974.

Moran, C.J., Walters, T.D., Guo, C.H., Kugathasan, S., Klein, C., Turner, D., Wolters, V.M., Bandsma, R.H., Mouzaki, M., Zachos, M., Langer, J.C., Cutz, E., Benseler, S.M., Roifman, C.M., Silverberg, M.S., Griffiths, A.M., Snapper, S.B., and Muise, A.M. 2012. IL-10R polymorphisms are associated with very-early-onset ulcerative colitis. Inflamm. Bowel. Dis. 19(1):115-123. doi: 10.1002/ibd.22974.

Mottet, C., Uhlig, H.H., and Powrie, F. 2003. Cutting edge: cure of colitis by $\mathrm{CD} 4+\mathrm{CD} 25+$ regulatory $\mathrm{T}$ cells. J. Immunol. 170:3939-3943. PMID: 12682220. doi: 10.4049/jimmunol.170.8.3939.

Murai, M., Turovskaya, O., Kim, G., Madan, R., Karp, C.L., Cheroutre, H., and Kronenberg, M. 2009. Interleukin 10 acts on regulatory $\mathrm{T}$ cells to maintain expression of the transcription factor Foxp3 and suppressive function in mice with colitis. Nat. Immunol.
10(11):1178-1184. PMID: 19783988. doi: 10.1038/ ni. 1791 .

Nepom, G.T., Byers, P., Seyfried, C., Healey, L.A., Wilske, K.R., Stage, D., and Nepom, B.S. 1989. HLA genes associated with rheumatoid arthritis: identification of susceptibility alleles using specific oligonucleotide probes. Arthritis Rheum. 32(1):15-21. PMID: 2492197. doi: 10.1002/anr.1780320104.

Parkes, M., Barrett, J.C., Prescott, N.J., Tremelling, M., Anderson, C.A., Fisher, S.A., Roberts, R.G., Nimmo, E.R., Cummings, F.R., Soars, D., Drummond, H., Lees, C.W., Khawaja, S.A., Bagnall, R., Burke, D.A., Todhunter, C.E., Ahmad, T., Onnie, C.M., McArdle, W., Strachan, D., Bethel, G., Bryan, C., Lewis, C.M., Deloukas, P., Forbes, A., Sanderson, J., Jewell, D.P., Satsangi, J., Mansfield, J.C., Wellcome Trust Case Control Consortium, Cardon, L., and Mathew, C.G. 2007. Sequence variants in the autophagy gene IRGM and multiple other replicating loci contribute to Crohn's disease susceptibility. Nat. Gene. 39 (7):830-832. doi: 10.1038/ng2061.

Podolsky, D.K. 2007. Inflammatory bowel disease. N. Engl. J. Med. 347(6):417-429. doi: 10.1056/NEJMra 020831.

Roifman, C.M. 2000. Human IL-2 receptor a chain deficiency. Pediat. Res. 48(1):6-11. PMID: 10879793. doi: 10.1203/00006450-200007000-00004.

Roifman, C.M., Gu, Y., and Cohen, A. 2006. Mutations in the RNA component of RNase mitochondrial RNA processing might cause Omenn syndrome. J. Allergy Clin. Immunol. 117(4):897-903. PMID: 16630949. doi: 10.1016/j.jaci.2006.01.003.

Rubtsov, Y.P., Rasmussen, J.P., Chi, E.Y., Fontenot, J., Castelli, L., Ye, X., Treuting, P., Siewe, L., Roers, A., Henderson, W.R. Jr., Muller, W., and Rudensky, A.Y. 2008. Regulatory T cell-derived interleukin-10 limits inflammation at environmental interfaces. Immunity. 28(4):546-558. PMID: 18387831. doi: 10.1016/j. immuni.2008.02.017.

Smeets, T.J.M, Kraan, M.C., Versendaal, J., Breedveld, F. C., and Tak, P.P. 1999. Analysis of serial synovial biopsies in patients with rheumatoid arthritis: description of a control group without clinical improvement after treatment with Interleukin 10 or placebo. J. Rheumatol. 26:2089-2093. PMID: 10529122.

Stastny, P. 1976. Mixed lymphocyte cultures in rheumatoid arthritis. J. Clin. Invest. 57(5):1148-1157. PMID: 1262462. doi: 10.1172/JCI108382.

Stoll, M., Corneliussen, B., Costello, C.M., Waetzig, G. H., Mellgard, B., Koch, W.A., Rosenstiel, P., Albrecht, M., Croucher, P.J., Seegert, D., Nikolaus, S., Hampe, J., 
Lengauer, T., Pierrou, S., Foelsch, U.R., Mathew, C.G., Lagerstrom-Fermer, M., and Schreiber, S. 2004. Genetic variation in DLG5 is associated with inflammatory bowel disease. Nat. Genet. 36(5):476-480. PMID: 15107852. doi: 10.1038/ng1345.

Weyand, C.M., Hicok, K.C., Conn, D.L., and Goronzy, J. J. 1992. The influence of HLA-DRB1 genes on disease severity in rheumatoid arthritis. Ann. Intern. Med. 117(10):801-803. PMID: 1416553. doi: 10.7326/ 0003-4819-117-10-801.

Xavier, R.J., and Podolsky, D.K. 2007. Unravelling the pathogenesis of inflammatory bowel disease. Nature. 448(7152):427-434. PMID: 17653185. doi: 10.1038/ nature 06005 . 